\title{
[1] \\ WHY AREN'T ECONOMISTS AS IMPORTANT AS \\ GARBAGEMEN?
}

\author{
David Colander
}

Say that all garbagemen got together and went on strike. What would the effect on society be? The answer is clear: Society would be a mess. Now say that all economists got together and went on strike. What would the effect on society be? Most people's answer would be, "None. Things would be just about the same with or without economists." Hence the question: Why aren't economists as important as garbagemen?

That rhetorical question sets up an unfair comparison. To contrast the two roles adequately, one would need to qualify the comparison in innumerable ways, but it does highlight economists' lack of a direct role in the everyday functioning of the economy.

Many of the articles in this issue discuss what economists' role is not. The Survey of Legislative Assistants and Stephen Quick's article point out that economists do not play a significant role in the development of laws; James Harasimowicz's Survey of Economic Journalists points out that economists do not play a significant role in transmitting ideas to journalists. The article by Robert Zevin points out that, when economists appear as consultants, their role is often a cameo-their advice is used if it supports what the proponents want and totally ignored if it does not. Moreover, as discussed by Alfred Malabre and documented by Terry Plum, an entire movement in economics-supply-side economics-can develop, influence policy, and fade away with little or no input from economists. Put simply, economists are not directly involved in the functioning of the economy.

In this lack of direct involvement, economics differs from many other professions. For example, in the above comparison, were one to replace economists with doctors, lawyers, or engineers, one's answer would be different; although these groups are still not as directly important as garbagemen, they play a more integral role in the everyday functioning of society. ${ }^{1}$

Economists' role could be different; there are numerous more active roles economists could play. For example, they might follow the lawyer pattern and play

1. No value judgments are being made here about what type of role a group should play. Shakespeare may have been right: Society might be better off if lawyers played no role. My point is simply that if lawyers were eliminated, it would have an immediate effect on the economy; if economists were eliminated, it would not. 
a "certification" role: Any law Congress passed that affected the economy and any decision business executives made that significantly affected the economy, such as plant closings or price changes, might require certification as "economically healthful" by a council of economic advisors. Thus, before a tax cut could be instituted or a major public works program begun, the proposals would need to be ruled upon by an independent economic judiciary.

A less-directly involved role might be modeled on doctors' or engineers' roles. If a doctor says you need an operation, you might get a second opinion, but if the two doctors concur, you are likely to have the operation. To some degree, this currently happens with economists, but, more often than not, economists' experience instead parallels that discussed by Zevin. Economists' specialized knowledge is used to support already decided-upon positions, is ignored, or is used in a "cover your backside" role. ${ }^{2}$ Somehow, policymakers simply do not believe that economists' specialized knowledge is a necessary input into the decisionmaking process.

It is not surprising that economists are not perceived in the same light as doctors or lawyers. Whereas a majority of doctors and lawyers practice medicine and law, the majority of Ph.D. economists teach; few economists "practice" economics. This means that when doctors and lawyers teach, they are teaching how to "do" law and medicine; when economists teach, because they are not "doing" economics, what they teach is not necessarily determined by what economists do.

At many community colleges and less prestigious four-year colleges, where faculty are given course loads of four or five courses per semester, economists have no time for anything but teaching. At the more prestigious four-year colleges and at universities, that teaching function is complemented by a research function that takes as much, or more, of the economists' time as does their teaching. A "normal teaching load" is two to three classes meeting a total of three hours per week for two fifteen-week semesters. That is a total of 225 hours per year or about 4.5 hours per week with four weeks off for vacation. At research universities, teaching loads are about half that. Academic bureaucracy, course preparation, grading, and following the literature take varying amounts of time, but assuming economists devote twenty hours a week to these activities during the school year, at the higher level schools, economists can devote half their time to research. Economists' role in the functioning of society comes from this research.

When economists talk to other economists about their work, it is this research that they are talking about. Graduate schools are designed primarily to prepare economists to conduct this research, and economists' indirect influence on the policies and activities of government and business stems in large part from this

2. If an individual can argue to his boss that he relied upon the best (interpret "most expensive") advice, he cannot be blamed when things go wrong. 
research. Considering the nature of this research clarifies why economists' role is indirect. Their research is basic, rather than applied, and even the applied research is generally presented in a form that is unintelligible to noneconomists; little or no interpretation is provided. Its effect on policy, if it has an effect, occurs through interpreters.

Focusing on basic research is not necessarily bad; nor does engaging in these pursuits mean that economists' role is smaller than other professionals. It does, however, make their role indirect. Keynes may well be right; economists' long-run indirect role may be of major importance for the economy: Monetary policy, fiscal policy, and the market itself are tombstones to earlier economists' scribblings. Economists' research has also provided an empirical basis that will underlie future policy changes and that limits others in their excessive claims for new policies. For example, although economists did not play a direct role in the supply-side revolution, their empirical work provided a counterweight to supply-side enthusiasm. Thus, economist-bashing is not in order.

Despite their successes, there is a lingering concern about the relevance of much of that research. When teaching others about a subject becomes the main activity of a profession, the subject matter can become more and more removed from what the profession is teaching about. The subject can become self-contained; it can lose its focus, and the research can become elaborate mind games designed to give students hoops to jump through and economists activities to keep them occupied, rather than contributing to our economic understanding. There are indications that this has happened in economics. The questions economists debate seem to many to be the modern-day equivalent of such scholastic questions as "God is omnipotent; can He create a rock so heavy He cannot lift it?" While debating these "important" questions, economists leave the "unimportant" questions of policy implementation to lawyers, politicians, and special interest groups.

Economists' role has not always been indirect. When economics began, teaching was a sideline; economists wrote for policymakers rather than for economists. Classical economists used contextual heuristic arguments that required a reader to bring to the reading of their work a sensitivity to institutions, politics, and moral considerations. They would make arguments that "made sense" to a normal lay reader and were designed to convince that reader.

As economics evolved in the nineteenth and twentieth centuries it moved away from the contextual argumentation that required the reader and writer to share a sense of the institutional framework and into noncontextual argumentation in which the assumptions and institutional framework of their argument were precisely spelled out. Economists came to wear two hats and used contextual or noncontextual arguments, depending on the audience. By the late 1960s, the formal techniques necessary to undertake the noncontextual arguments had become so great 
that younger economists were no longer being trained to know about real world institutions, a requirement if one is going to talk seriously about policy. ${ }^{3}$

Unless an economist has inherent or independently acquired abilities in communicating ideas to the outside world, becoming an economist is like joining a priesthood sworn to communicate only among its members. For economists, if one's arguments can be understood by outsiders they are obviously too simple; and if one's work has direct policy relevance, one must be doing something wrong. ${ }^{4}$ With such beliefs, it is little wonder that economists are less important to the everyday functioning of the economy than are garbagemen.

Many economists, citing the reasons given above, argue that this separation between economists and the public is necessary. They argue that physicists and mathematicians are not required to communicate with the general public; why should economists? I agree with this argument for a small few in the profession, but there are many more economists than theoretical physicists, and most are not working on the borders of our understanding. Thus, in the case of the majority of economists, I disagree; their role should be similar to that of doctors or engineers. For them, communicating their research to the general public should be an important consideration.

\section{ECONOMISTS' PERCEPTION OF THE ROLE IN SOCIETY}

Economists do not play a more direct role because they have a fundamentally incorrect view of the nature of their role. In his article, Robert Heilbroner nicely captures the way economists view society. They are trained to be detached-to view themselves as outside the economy-looking down from above. From that perspective, they make judgments on how well the economy is functioning. This is in direct contrast to individuals who view society from their own perspective: When faced with a problem, most people ask, "How will it affect me?" Economists ask, "How will it affect society?" Economists see themselves as outside judges.

Placing any group in an outside position "judging society" is a dangerous undertaking. One is left with the problem: Who will judge the judges? Economists have taken this concern to heart and have worked hard at eliminating their own individualistic perspective and replacing it with "society's perspective." As Heilbroner argues, economics has not been totally successful in eliminating values from its analysis, but it has been partially successful.

\footnotetext{
3. In a survey of graduate students that Arjo Klamer and I did, three percent of the students thought institutional knowledge was important to getting on the fast track in economics; 68 percent thought it unimportant.

4. When Robert Lucas, a top theoretical macroeconomist, was asked what he would do if he were appointed chairman of the Council of Economic Advisors, he quipped, "I would resign."
} 
Unfortunately, economists' Don Quixote-like quest for the ideological purity of a value-free perspective has come at a cost. In trying to achieve the impossibleavoiding all value judgments in their analysis-they have eliminated their direct role in policy.

In order to stay out of the fray, economists have retreated into pure theory and basic research, leaving others the "unimportant" role of interpreting the "pure theory" and applying the ideas to society. It is as if a judge, for fear of bringing his own, rather than the law's, perspective to a case, will decide only hypothetical cases.

Taking an outside perspective and attempting to remain value-free is wrong, but not, as Robert Heilbroner suggests, because it is impossible. The fact that it is impossible to be totally value-free does not mean that economists should not attempt to be as value-free as possible. It is wrong because it is too heavy a burden for any group to bear. Economists are not the judges of the economy; society is. Economists are inside society; their existence as a group reflects society's investment in protecting, modifying, and changing economic institutions.

Viewing economists from an inside perspective changes the nature of their role. They are not gods who have little need to communicate with policymakers; a bit of ideological impurity will not destroy their role. Their role is to study the economy and to present their conclusions (derived from maintaining as outside a perspective as possible) and to argue their case to the public as strongly as they can. If the public accepts it, fine; if not, that is also fine. Their work is simply one input into the decision-making process; it is not the final pronouncement. Recognizing this more limited role for economists is humbling for them, but it also frees them to take a more active direct role in policy formation without their current excessive concern that they might include some of their own value judgments in their prescriptions.

\section{THE PROBLEM WITH AN OUTSIDE PERSPECTIVE}

The problem of taking an outside perspective can be seen in economists' thinking about the economy. Taking an outside perspective, one is godlike and is led inevitably to one of two positions: that one should keep one's hands off societylaissez-faire-or that one should change society because one knows best. Both these positions are mistaken and do not capture the role economists should be playing in society.

Liberal economists have been willing to argue, generally implicitly, that they know best. Logically, this position cannot be held simultaneously with the position that individuals are rational and know best, but liberal economists do not push economic logic to extremes. They find room for new ideas and policy initiatives in economics even while using both the assumption of individual rationality and 
an "outside" perspective. But they can do so only by making logical jumps that conservatives delight in pointing out.

A few, generally conservative, economists push economic logic to its extremes and arrive at the conclusion that there is no room for economic policy. Examples of this reasoning pervade economics; they include some versions of the invisible hand theorem, aspects of the public choice literature, the Coase theorem, New Classical economics, and the efficient market hypothesis. What all these arguments have in common is that they lead to a laissez-faire policy prescription because economists begin with an assumption that individuals are rational and that whenever they can make a gain from trade they will. Economists then ask what possible role there might be for government intervention, which makes everyone better off than they would be on their own. Because any action worth doing would already have been done by rational individuals, given the assumption, the laissez-faire conclusion is preordained.

Now, I am not arguing that government intervention is good and laissez-faire bad. I am simply arguing that the laissez-faire conclusions and all the theorems and arguments associated with them are tautologically correct if the judge is viewing society from an "outside" perspective. They are also irrelevant. The arguments state no more than "what is, is."

To see why the outside perspective is wrong, consider a similar problem of perspective in making judgments about the ecological system. The ecological system is evolving. What role should humankind play in that evolution? The "outside" perspective places humankind outside of nature. From this outside perspective, if an animal or plant changes the environment, that is as it should be-nature's way. If humans change the environment-say, by devising a new chemical process - that is unnatural and, by implication, bad.

On a logical level, why should humans' actions be any less "natural" than animals' actions? If humans are unnatural, then they have been unnatural forever, and their actions, including domestication of plants and animals-agriculture, reading, and thinking - are unnatural. But were humans not to have taken such actions, society would not be what it is, and what we are calling natural would not exist. Relying on natural/unnatural categorization places humankind outside of nature when, in fact, men and women and their ways of dealing with life are as much part of the natural processes (whatever they are) as are animal, vegetable, and physical operations.

In order to undertake policy, actions must be divided into good actions and bad actions, but the division is not synonymous with the natural/unnatural division. All policy actions that humans suggest are not unnatural and therefore bad, but that is the logical conclusion that one inevitably arrives at if we use the "outside" rather than the "inside" perspective. 
Because economists take an outside perspective, that same natural/unnatural dichotomy pervades economic terminology. They use terms such as "the natural rate of interest" and "the natural rate of unemployment" in much the same way that people use "natural food": as a way to convey that the phenomenon is as it should be. But just as is the case with ecology, the separation of actions into two sets, natural and unnatural, is not a helpful way of looking at society.

I am not arguing that the outside perspective should not be the economists'. I am simply arguing that in their analysis they must remember that they ultimately remain inside the economic system. Having decided what is best from their attempt at taking an outside perspective, they must play an inside role in implementing their proposals, convincing others that their policy proposals are good for society. Doing so is as much a part of the economists' function as providing an understanding of the economy. Unless economists convince society that their policy recommendations are best, their policy recommendations are not best. Economists cannot stand on any moral higher ground. Their ideas are as subject to the intellectual marketplace as lawyers' and politicians'.

The inside perspective avoids the logical problems of suggesting policy changes from an outside perspective. It answers the question of how, if individuals are doing everything in their power to make themselves as well off as possible, a policy government could implement could make people better off. From an inside perspective, laissez-faire policies cannot be deductively arrived at from the model. If laissez-faire were optimal, society would not have designated a group of peopleeconomists-to study how to improve the economy. One might conclude that a laissez-faire policy is preferable, but it is a conclusion to be arrived at in comparison with other policies; it is not a priori.

From within, economists cannot say, on the basis of what is natural (or efficient) and what is not, "The government should, or should not, intervene." "'This policy should be introduced." "This policy should not." In making judgments from an inside perspective, these criteria no longer pertain; there are no outside criteria to judge by. Efficiency is no longer an end in itself; it is simply one attribute of a policy that economists can use to convince policymakers of its desirability. Instead of stating that "this policy is best because it is more efficient," their arguments for a policy will be on the basis of the policy's effect on society. Their arguments will be more like: "This policy will change society in this way." "Here is what society will be like with this policy." "Here is what society will be like without this policy." Their arguments will include all aspects of a policy, including income distribution effects, administrative costs, and political feasibility.

\section{CONCLUSION}

Learning how to play this inside role would change the nature of economic education. Students would learn how to argue, how to write, and how to make 
contextual, as well as noncontextual, arguments. They would learn how to explain their ideas, how to modify theoretical notions, and how to make them fit into the political and social realities. Similarly, what the research economists do would change, and the pure research about the "important" questions would be supplemented by the research about the "unimportant" questions, such as what policy firms or government should undertake.

Changing perspective will not make economists more important than garbagemen. Garbagemen are naturally more important than most other groups in society. The change will, however, play a role in increasing economists' direct impact on society, not to the level of lawyers (God help us [society] should that happen), but perhaps to the level of doctors or dentists. Keynes once said, "If some say we could manage to get ourself thought of as humble, competent people, on a level with dentists, that would be splendid." Changing to an inside perspective would be one small step for humility and competence. Whether that step will make society better off is debatable, but it will make economics a more meaningful profession. 